\title{
Are there good reasons for the fluoride labelling of food and drink?
}

FV Zohoori ${ }^{1}$, A Maguire ${ }^{2}$

1 School of Health \& Social Care, Teesside University, UK

2 Centre for Oral Health Research, School of Dental Sciences, Newcastle University, UK

Corresponding author:

Professor Vida Zohoori;

Health and Social Care Institute

Teesside University

Middlesbrough, TS1 3BA

In brief:

- It's important to control systemic fluoride intake from food and drink in early childhood to minimise risk of dental fluorosis whilst maximising caries prevention.

- A study of commercially-available food and drinks found a wide range of fluoride content ( $\mu \mathrm{g}$ fluoride per $100 \mathrm{~g}$ of the product).

- Comprehensive fluoride labelling is needed on food and drink products in the UK, particularly those used by infants and young children. 


\section{Introduction}

The global decline in the prevalence of dental caries is largely due to the widespread available and use of fluorides. The dental health benefits of naturally fluoridated waters were recognised well over a century ago now and subsequent optimisation of the fluoride concentration of drinking waters through artificial water fluoridation, introduced more than 60 years ago, is considered to be one of the ten most significant public health interventions of the $20^{\text {th }}$ century. Currently 25 countries, including the UK, the USA, and Australia, have artificial water fluoridation schemes reaching approximately 369.2 million consumers ${ }^{1}$. Inclusion of those drinking naturally fluoridated water brings the total number of people consuming optimally fluoridated water to around 437.2 million ${ }^{1}$ representing almost $6 \%$ of the world's population. More ubiquitous in terms of fluoride exposure has been the increasingly worldwide access to fluoridated toothpastes for nearly 50 years now. While the evidence base for the dental effects of topical fluoride use is strong, the riskbenefit associated with systemic exposure to ingested fluorides is a more difficult scenario since excessive systemic ingestion of fluorides during dentally vulnerable periods can increase the risk of development of dental fluorosis, characterised by degrees of intrinsic tooth discoloration (tooth mottling).

Although the critical period for development of fluorosis in late developing primary teeth is from four months in utero until 11 months of $a^{2} \mathrm{e}^{2}$, enamel fluorosis on the permanent anterior teeth is most likely to result from excessive fluoride ingestion during the first five years of life with the most significant period being the first three years ${ }^{1}$. Whilst a total fluoride

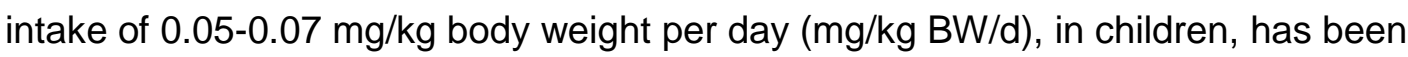
suggested as optimum for dental health benefits, the fluoride intake should not exceed a tolerable upper intake level (UL) of $0.1 \mathrm{mg} / \mathrm{kg} \mathrm{BW} / \mathrm{d}$, especially during enamel formation, to minimise the risk of dental fluorosis ${ }^{3}$.

Several reports ${ }^{4}$ from western countries have shown an increase in the prevalence of mostly very mild to mild dental fluorosis including a relatively recent UK study ${ }^{5}$, in children aged 1113 years, which indicated a dental fluorosis prevalence (at any severity level) of $55 \%$ in fluoridated areas and $27 \%$ in non-fluoridated areas.

Despite dental fluorosis being a side-effect of chronic excessive ingestion of fluoride, rather than an adverse health concern, perceptions of mild and moderate levels remain a contentious issue. A cross-sectional national survey in the $\mathrm{UK}^{6}$ reported that $29 \%$ of the study population perceived a 'need for treatment' for mild levels of fluorosis, while it was $69 \%$ at moderate levels and $91 \%$ at severe levels of fluorosis.

Considering the narrow 'dose-gap' between caries reduction benefit and dental fluorosis risk, the issue of monitoring fluoride intake in young children was raised by the World Health Organisation ${ }^{7}$. More recently, controlling fluoride ingestion has regained the attention of 
researchers around the world due to the reported rise in the prevalence of dental fluorosis in both fluoridated and non-fluoridated areas ${ }^{8}$.

The total amount of fluoride intake, from all sources, has been suggested as the most important risk factor for development of dental fluorosis ${ }^{9}$. Common sources of ingested fluoride include diet (including fluoridated water, foods and drinks prepared with fluoridated water or containing fluoride naturally), dietary fluoride supplements (such as fluoridated milk and salt), non-dietary fluoride supplements (e.g. fluoride tablets), and inadvertent ingestion of fluoridated toothpastes. Although toothbrushing with a fluoridated toothpaste is a major source of fluoride intake for children, data from fluoride intake studies in the UK have shown diet to be the sole source of fluoride intake for the majority of infants (up to 6 mo of age) with a fluoride intake of up to $0.18 \mathrm{mg} / \mathrm{kg} \mathrm{BW} / \mathrm{d}^{10}$. Similarly, in the US, the 'lowa Fluoride Study' reported that during the first 12 months of age, up to $96 \%$ of total fluoride intake can be from diet, which then decreases to $53 \%$ at age 24 months ${ }^{11}$.

The identification of infant milk formula (IMF) as a risk factor for having dental fluorosis prompted manufacturers to voluntarily reduce the fluoride content of their IMF powder in several countries including the US and Australia ${ }^{12}$. Nevertheless, the association between IMF feeding and dental fluorosis has been the matter of debate in recent years ${ }^{1}$ as some studies have shown that fluoride concentration $(\mu \mathrm{g} / \mathrm{ml})$ of water used to reconstitute powdered IMF could have a greater impact on the fluoride intake of formula-fed infants than the fluoride concentration of the powdered formula itself ${ }^{10,13}$.

With trends towards greater use of convenience products such as ready-to-feed infant food and drinks, not only the choice of infant feeding method (eg. Breast- or Formula-fed) but also the type of weaning food/drinks used by infants and very young children can have a profound impact on their dietary fluoride intake. Recent UK studies have indicated that some infant products contain a relatively high fluoride concentration; for example, ready-to-feed meat-based weaning foods with a fluoride concentration of up to $1.20 \mu \mathrm{g} / \mathrm{g}^{14}$.

\section{Fluoride "flow" and the "halo" effect}

Any excessive systemic fluoride intake of significance to dental fluorosis risk, occurs in early childhood, while topical fluoride exposure of significance to dental health benefit occurs across the whole life course. Ingestion of fluoride through diet does not pose a risk of development of dental fluorosis in adults since most uptake of fluoride into teeth occurs during tooth development and eruption, the majority of which is complete by late childhood. The increasing within- and between- area and/or country movement of people and commodities, including food and drink make it difficult to establish any links between total fluoride exposure and health outcomes. 
Bottled water use and consumption of ready-to-drink beverages as well as processed and ready-to-eat foods has become increasingly common worldwide. This increasing globalisation of the food and drink industry means that products (including bottled waters) from a fluoridated area may be transported to a non-fluoridated area for consumption and vice-versa, producing a "halo" effect.

In addition to this effect, the fluoride concentration of these products, which come from many sources, can be highly variable making fluoride intake from these products difficult to measure in the community. For example, a study in Spain reported a wide range of fluoride concentration (0-4.16 ppmF) in mineral waters bottled in Spain, whereas imported brands had a range from 0.10 to $1.21 \mathrm{ppmF}^{15}$. That study also reported that only $<26 \%$ of brands specified the fluoride content ( $\mu \mathrm{g}$ fluoride per $100 \mathrm{~g}$ of the product) on the label. Another study ${ }^{16}$ in the US (Indianapolis) reported that some of the analysed bottled waters targeted for infants did not comply with the American Dental Association (ADA) recommendation ${ }^{17}$ to prevent fluorosis which states; "The (ADA expert) panel offers the following suggestions to practitioners to use in advising parents and caregivers of infants who consume powdered or liquid concentrate infant formula as the main source of nutrition: - Suggest the continued use of powdered or liquid concentrate infant formulas reconstituted with optimally fluoridated drinking water while being cognizant of the potential risk of enamel fluorosis development; When the potential risk of enamel fluorosis development is a concern, suggest ready-to-feed formula or powdered or liquid concentrate formula reconstituted with water that either is fluoride-free or has low concentrations of fluoride".

Understanding "fluoride flow" within its "source-production-consumption" environment and being able to monitor systemic fluoride exposure are key to promoting the benefits of fluorides while minimising risks from chronic over-exposure. Information on the fluoride content of commonly consumed food and drink items is therefore a pre-requisite to enable assessment of dietary fluoride intake at individual and/or community levels.

\section{Creation and maintenance of a fluoride database}

A fluoride database ${ }^{14}$ developed and populated by Teesside and Newcastle universities includes the fluoride concentration ( $\mu \mathrm{g}$ fluoride per $1 \mathrm{~g}$ of the product) and content ( $\mu \mathrm{g}$ fluoride per $100 \mathrm{~g}$ of the product) of a substantial number of food and drink products sold within the UK, representing brands manufactured by leading companies in the European food market. The database is intended as a tool for public health professionals and policymakers to facilitate monitoring of dietary fluoride intake, particularly in children. While useful, the database has some limitations since, as with any element/nutrient, the fluoride content of a similar food or drink product might not be exactly as that recorded in the database because of natural variability in nutrient composition of the product which may be due to different 
factors. For example, the composition of animal products could be influenced by age, feeding routine and season. In addition, factors such as the country of origin and local growing conditions could affect the composition of plant products, while alteration in recipes, amounts and types of ingredients and even the material composition of the cooking vessel can affect the fluoride content of a particular product.

It is important that the public take responsibility for their health; parents need to make the best decisions for their young children while health professionals must provide comprehensive advice to their patients/clients to allow this to happen. To facilitate this, the provision of appropriate access to current information intended to help decision-making in dietary choice is key.

\section{A call for fluoride labelling}

The wide range of fluoride content within food and drink groups, verified within the UK fluoride database clearly highlights the need for comprehensive fluoride labelling of food and drink products, particularly those used primarily by infants and very young children. Nutrition labelling is an information tool meant for consumers and organised by the public authorities in collaboration with representatives of all stakeholders including the food industry, public and regulators. Information provided on food product packaging helps consumers build knowledge and develop their plans for consuming a healthy diet as well as choosing between different foods, brands and flavours. In the case of fluoride exposure, monitoring fluoride intake is a difficult and time-consuming task which involves assessment of fluoride ingestion from diet and toothpaste ingestion, whereas controlling ingestion of fluoride is a more practical and feasible alternative approach which would be facilitated by the labelling of fluoride content of food and drink products.

In Europe, nutrition labelling has been a legal obligation since 1990. However, the European Union Food Information Regulation (EU FIR) came into force in December 2011 and mandatory nutrition declarations for most prepacked foods came into effect from December 2016. The EU FIR specifies the information which must be made available to consumers when they buy food and how that information must be presented. This mandatory information includes: energy, fat (and the proportion of which is saturates), carbohydrates (and the proportion of which is sugars), protein and salt. However, declaration of vitamin and mineral content per $100 \mathrm{~g}$ is classed as supplementary information ${ }^{18}$.

Although fluoride is not generally regarded as an essential element, it is considered to be an important nutrient due to its caries-prevention properties and is included in the list of ultratrace elements (an element with an established or estimated requirement, generally indicated in $\mu \mathrm{g} /$ day for humans $)^{19}$. 
Currently, the inclusion of information on the fluoride content of food and drink products by manufacturers is voluntary. Some baby food manufacturers have started to voluntarily declare the fluoride content of a limited number of their products such as IMFs. However, in view of the importance of maintaining topical exposure to fluorides but avoiding excessive systemic intake, especially during "tooth-vulnerable" periods, manufacturers (particularly baby and toddlers' food and drinks manufacturers) should be encouraged to label the fluoride content of their products alongside other currently included minerals. In particular, bottled water labels should indicate whether they are suitable for consumption by infants and very young children. This would help ensure manufacturers monitored and controlled the fluoride content of their products to meet guidelines for intake, for example, by using nonfluoridated waters for production, providing more choices for consumers.

\section{A possible post-Brexit approach?}

According to the current legal requirements of the Natural Mineral Water, Spring Water and Bottled Drinking Water (England) Regulations $2007^{20}$, the maximum limit for any naturally present fluoride concentration of natural mineral water is $5 \mathrm{mg} / \mathrm{l}$, with a specific requirement for the labelling of bottled water with fluoride concentrations $>1.5 \mathrm{mg} / \mathrm{l}$, which should state; "contains more than $1.5 \mathrm{mg} / \mathrm{l}$ of fluoride; not suitable for regular consumption by infants and children under 7 years of age" and the inclusion of the actual fluoride content on the label. With the UK leaving the EU, an opportunity for review of UK food labelling policy after Brexit arises and the labelling of fluoride content of food and drink products is a pertinent area for improvement.

Projects such as the five-year (2014-2018) Food Integrity Project (FIP) ${ }^{21}$, funded by the European Union's Seventh Framework Programme for research and technological development, might be a suitable approach to encourage/enforce manufacturers to specifically label their products for fluoride content. The FIP which includes 60 participating bodies from 18 European countries, is working with industry to develop methods and processes that assure the quality and safety of the food chain and is focusing on reducing the current barriers to data sharing and utilisation.

In 2015 , the UK imported $€ 44$ billion worth of food and drink products, of which $€ 31$ billion (70\%) came from the EU while it exported $€ 15$ billion worth of similar products, of which $€ 11$ billion (73\%) went to the $\mathrm{EU}^{22}$. The size of this market creates an ideal opportunity for the UK authorities to take a strong lead in improving the labelling of products with the goal of improving general and oral health. 
References:

1 O'Mullane D M, Baez R J, Jones S, et al. Fluoride and Oral Health. Community Dent Health 2016; 33:69-99.

2 Warren J J, Levy S M, Kanellis M J. Prevalence of dental fluorosis in primary dentition. J Public Health Dent 2001; 61:87-91.

3 Burt B A. The changing patterns of systemic fluoride intake. J Dent Res 1992; 71:122837.

4 Pendrys D G. Risk of enamel fluorosis in nonfluoridated and optimally fluoridated populations: considerations for the dental professional. J Am Dent Assoc 2000; 131:746-55.

5 McGrady M G, Ellwood R P, Maguire A, Goodwin M, Boothman N, Pretty I A. The association between social deprivation and the prevalence and severity of dental caries and fluorosis in populations with and without water fluoridation. BMC Public Health $2012 ; 12: 1122$.

6 Alkhatib M N, Holt R, Bedi R. Aesthetically objectionable fluorosis in the United Kingdom. Br Dent J 2004; 197:320-323.

7 Marthaler T H. Monitoring of renal fluoride excretion in community preventive programmes on oral health. Geneva: World Health Organisation (WHO), 1999.

8 Buzalaf M A, Levy S M. Fluoride intake of children: considerations for dental caries and dental fluorosis. In Buzalaf M A (ed) Monogr Oral Sci. Vol 22. pp 1-19. Basel: Karger, 2011.

9 Hong L, Levy S M, Broffitt B, et al. Timing of fluoride intake in relation to development of fluorosis on maxillary central incisors. Community Dent Oral Epidemiol 2006; 34:299309.

10 Zohoori F V, Whaley G, Moynihan P J, Maguire A. Fluoride intake of infants living in non-fluoridated and fluoridated areas. Br Dent J 2014; 216:E3.

11 Levy S M, Warren J J, Davis C S, Kirchner H L, Kanellis M J, Wefel J S. Patterns of fluoride intake from birth to 36 months. J Public Health Dent 2001; 61:70-77. 
12 Do L G, Levy S M, Spencer A J. Association between infant formula feeding and dental fluorosis and caries in Australian children. J Public Health Dent 2012; 72:112-121.

13 Zohoori F V, Moynihan P J, Omid N, Abuhaloob L, Maguire A. Impact of water fluoride concentration on the fluoride content of infant foods and drinks requiring preparation with liquids before feeding. Community Dent Oral Epidemiol 2012; 40:432-440.

14 Zohoori F V, Maguire A. Development of a Database of the Fluoride Content of Selected Drinks and Foods in the UK. Caries Res 2016; 50:331-336.

15 Maraver F, Vitoria I, Almerich-Silla J M, Armijo F. Fluoride content of bottled natural mineral waters in Spain and prevention of dental caries. Aten Primaria 2015; 47:15-24.

16 Steinmetz J E A, Martinez-Mier E A, Jones J E, et al. Fluoride Content of Water Used to Reconstitute Infant Formula. Clin Pediatr (Phila) 2011; 50:100-105.

17 Berg J, Gerweck C, Hujoel PP, et al. Evidence-based clinical recommendations regarding fluoride intake from reconstituted infant formula and enamel fluorosis: a report of the American Dental Association Council on Scientific Affairs. JADA 2011; 142:79-87.

18 Food Standards Agency. Nutrition Labelling Requirements under the Food Information to Consumers Regulation (EU) No. 1169/2011. Online information available at https://www.food.gov.uk/sites/default/files/nutritionlabellinginformationleaflet.pdf (accessed August 2017)

19 Nielsen $\mathrm{F} \mathrm{H}$. Ultratrace elements in nutrition: Current knowledge and speculation. $J$ Trace Elem Exp Med 1998; 11:251-274.

20 Food Standards Agency. The natural mineral water, spring water and bottled drinking water (England) regulations 2007: Guidance to the legislation. Online information available at https://www.food.gov.uk/sites/default/files/multimedia/pdfs/waterguideeng07updated.pdf (accessed December 2017).

21 The Food Integrity Project. Online information available at https://secure.fera.defra.gov.uk/foodintegrity/index.cfm?sectionid=21 (accessed August 2017). 
22 Gira. BREXIT What's at stake for Suppliers of Food Products to and from the UK - A quantification and analysis of the main categories of UK food imports and exports at risk in the event of a Brexit. 2016. Online information available at http://agricultura.gencat.cat/web/.content/de departament/de02 estadistiques observat oris/27 butlletins/02 butlletins nd/documents nd/fitxers estatics nd/2016/0180 2016 PoliticaAgraria BREXIT-exportacions-importacions.pdf (accessed August 2017). 